\title{
George A. Akerlof and Robert J. Shiller: Animal Spirits: How human psychology drives the economy and why it matters for global capitalism
}

Princeton, New Jersey, Princeton University Press 2009, \$24.95, pp. 230

The current financial and economic crisis has, in the meantime, generated an abundance of economic literature. "Animal Spirit" by Akerlof and Shiller stands out from this crowd. This book is not intended to provide new or revamped familiar economic recipes for coping with the crisis, nor has it been written by authors who have converted to Keynesianism in light of recent events. Naturally, Akerlof and Shiller do develop economic advice. However, to them the crisis serves as a peg rather than as an opportunity to advocate a new orientation of economic theory. For the authors, Keynes' reference as to the power of "animal spirits" in "The General Theory" is a hint that it is recommendable to embed macroeconomic theory not only in psychology, but in sociology too. In brief, according to Akerlof and Shiller, the patient is not the economy, but economic theory, which was not capable of properly measuring and interpreting the economy's fever.

According to the authors, those "animal spirits" - the volatility of confidence due to desires, jealousy, disgruntlement, illusions and particularly action-driving stories on the state of the economy - have triggered this economic crisis, just as other economic crisis before. "Animal spirits" thus cover the whole array of irrational behavior as well as rational but noneconomic behavior in economics. Most decidedly, and without mentioning by name Vilfredo Pareto, let alone less economically oriented sociologists, Akerlof and Shiller ignore Pareto's demarcation that restricted economics to exploring the domain of rationality while committing sociology to specializing on the exploration of irrationality. In my opinion, they are implicitly following the basic idea of Talcott Parson of a voluntaristic action theory according to which each subsystem of society - that also includes the economy - has its own cultural, social, political - and in the case of the economy, dominant economic - ways of action. In a more contemporary formulation (and with a better theoretical solution than the one suggested in traditional structural functionalism), Akerlof and Shiller adhere to instrumental action in economic contexts as a rule; however, they acknowledge that economic behavior is embedded in social contexts and admit that - at least when seen from a strictly rational point of view - it is not free of irrationalities.

The authors concretize these basic considerations that are known in contemporary sociological notions of "rational choice", in five different forms of expression of the "animal spirits". This particularly encompasses trust and interaction between trust and economic activity. Two further characteristics are closely connected to this main pillar of their theory: on the one hand there is the idea of fairness, which influences pricing in general and wage setting in particular, and on the other hand there is the temptation of corruption and the resulting opportunist and antisocial behavior. While these extensions mainly affect sociological aspects of action theory, Akerlof and Shiller deal with mostly psychological aspects of economic behavior, such as the phenomenon of money illusion 
and the connected illusions about changes of price levels during inflationary or deflationary phases as well as perception- and action-driving stories.

One of the strong points of the text is that the authors do not confine themselves to programmatic announcements about a new conception of man for the fields of economics or social sciences but, in analyzing concrete economic problems, show how "animal spirits" contribute to an economic theory with a solid empirical foundation. In the chapter on fairness, for instance, they assume practical problems of wage setting to explain contemporary results of empirical field and experimental research on the perception of fairness and fair behavior as well as aspects of classic social exchange theory. The other chapters are structured similarly. Based on the question in what market areas consumer protection is particularly advisable - i.e. in those cases where the consumer cannot easily estimate the characteristics of a product - they explain chances for opportunistic behavior on markets for financial products, where problems with or failure of control have promoted corrupt and fraudulent behavior, offer advice on how money illusion can be explained in cognitive psychology, and discuss the importance of stories for organizing perception. In my opinion, the theoretical foundation of the latter construct is considerably weaker than in the case of the other "animal spirits." It is possible that the authors consider the importance of stories and storytelling for the "definition of the situation" (Thomas/Znaniecki 1918; March/Simon 1958) to be self-explanatory and therefore refrain from elucidating basic theoretic deliberations supporting this relation. In the context of this argument it would be worthwhile to elaborate on the connection to the sociological theory of "rational choice," in order to go into detail about the concept of rationality, e.g. according to Boudon's position and disposition effects (1989).

Nevertheless, in the course of the book, Akerlof and Shiller use the outlined theory of "animal spirits" to answer eight questions that are important in the context of the current financial crisis and the economic cycle in general. Even though the authors do not literally present a theory of economic cycles but rather concentrate their fields of research on cyclical problems, their explanations are of great interest, especially for business economists. On the one hand, the aspects of labor, education, manpower etc. that Akerlof and Shiller are dealing with have much in common with the sub-disciplines of business management. On the other hand, their work is topical even beyond the specialized aspects addressed. The theories of the sub-disciplines of business management all but depend on the deficits of economic theory construction. For those who expect this book to bridge the gap between economics and social sciences, Akerlof and Shiller certainly is a must read.

\section{References}

Boudon, R. (1989): The Analysis of Ideology. Chicago: Univ. of Chicago Press.

March, J. G./Simon, H. A. (1958): Organizations. New York et al: John Wiley.

Thomas, W. I.,/Znaniecki, F. (1918): The Polish Peasant in Europe and America: Monograph of an Immigrant Group. Vol. 1, Primary-Group Organization: Boston, Mass.: The Gorham Press.

Hamburg, November 11, 2009

Wenzel Matiaske*

Professor Wenzel Matiaske, Department of Economics and Social Sciences, HelmutSchmidt-University Hamburg, and German Socio-Economic Panel Study, German Institute of Economic Research (DIW/SOEP), Berlin. E-mail: matiaske@hsu-hh.de. 